\title{
The Long-Term Effectiveness of Empathic Interventions in Medical Education: A Systematic Review
}

This article was published in the following Dove Press journal:

Advances in Medical Education and Practice

\author{
Reginald F Baugh (D) \\ Margaret A Hoogland (iD) ${ }^{2}$ \\ Aaron D Baugh ${ }^{3}$ \\ 'Admissions, University of Toledo \\ College of Medicine and Life Sciences, \\ Toledo, OH 43623, USA; 'Library, \\ University of Toledo College of Medicine \\ and Life Sciences, Toledo, $\mathrm{OH} 43623$ \\ USA; ${ }^{3}$ Pulmonary, Critical Care, Allergy, \\ Sleep Medicine, University of California \\ San Francisco Medical Center, San \\ Francisco, CA 94I3I, USA
}

\begin{abstract}
The Association of American Medical Colleges recognizes that empathy is an important part of providing excellent patient care and lists empathy as a Core Entrustable Professional Attribute for physicians. This study is a review of the literature focusing on studies with an educational intervention to promote empathy and at least one year follow-up data. After reviewing the 4910 abstracts retrieved from PubMed, PsycInfo, Cochrane, Web of Science, CINAHL, and Embase; the coauthors selected 61 articles for full-text review and completed a medical education research study quality instrument (MERSQI) to ensure all selected studies scored at least 7 or above. Five studies from the US and seven international studies met our inclusion criteria and formed the basis for the study. Few longitudinal studies with a post-intervention follow-up exist to confirm or disprove the effectiveness and durability of empathy training. Of the published studies that do conduct long-term follow-up, study design and measures used to test empathy are inconsistent. Despite the high degree of heterogeneity, the overwhelming majority demonstrated declining empathy over time. Little evidence was identified to support the ability to augment the empathy of physician trainees in sustained fashion. A model is presented which explains the observed changes. Alternative solutions are proposed, including the selection of more prosocial candidates.
\end{abstract}

Keywords: empathy, empathetic training, empathetic motivation, medical education

\section{Plain Language Summary}

The movement of people is leading to greater diversity across the globe. This includes areas with little or no prior experience with people who are different. Students enter medical school with different empathic abilities and willingness to help people who are different from them. Medical educators try to teach empathy so that students can provide care to all patients. This review searched six major databases to examine the long-term effects of efforts to improve empathic ability and expression in medical students. Twelve long term studies were found. Unfortunately, the results of teaching empathy long-term were unsuccessful. Most of the studies were not done well. More long-term studies are needed. Picking people with a record of helping others may be more effective than trying to "teach" empathy.

\section{Introduction}

\section{Role of Empathy}

Empathy is a central component of quality clinical care and medical professionalism. It is at the "center" of the AAMC Core Entrustable Professional Activities. ${ }^{1,2}$ Each of the three facets of empathy, namely affective, cognitive, and motivational, is important and 
has to be adaptively engaged to positively influence patients' health. ${ }^{3}$ Once viewed as an innate character trait, it is now understood as a complex, dynamic, homophilic relational process based on the demands placed on individuals in the context of their environment. ${ }^{4}$ The study of empathy is challenging because of disagreements about its definition, weaknesses in study methodologies, and differences in the construct measured in past studies. ${ }^{5,6}$ The lack of consensus about the definition of empathy in medical education is bolstered by complex variables, including the relationship of an individual's attitudes, beliefs, and social and institutional norms. Significant individual variation in moral reasoning, cooperation, fairness, reasoning styles, self-concepts, and related motivations adds to definitional difficulties. ${ }^{7}$

These challenges notwithstanding, the topic represents an area of urgent concern within medical education. Low empathy scores have been associated with poor medical student clinical performance in the $\mathrm{UK}^{8},{ }^{8}$ the US, ${ }^{9}$ and Australia. ${ }^{10}$ It was therefore significant that Konrath identified a $40 \%$ decline in empathy among US college students from 1960-2000. ${ }^{11,12}$ Studies of future physicians have also identified declines in altruism below the mean of the general public, as well as increases in narcissism and cynicism. $^{13-15}$ Reductions in empathy, primarily associated with the clinical phase of medical school but occurring throughout medical training have also been widely reported; ${ }^{5,16}$ at least 18 articles have been published on the topic since $1955 .^{17}$

Following recommendations by the Association of American Medical Colleges 20 years ago, ${ }^{18}$ medical education has responded by "teaching empathy." Although "teaching empathy" is widely practiced, its efficacy is unclear. ${ }^{19}$ The effectiveness of short-term empathic training seems to vary according to student characteristics. Short-term empathic training is generally more effective in egalitarian students ${ }^{20,21}$ and those of Asian ancestry. $^{22-24}$ Specifically focused curricula ${ }^{25}$ have the greatest improvement in empathic capacity. In particular, this training improves perspective-taking and understanding of others' emotions, which are arguably most important to physician empathy, ${ }^{26}$ and most susceptible to change through teaching. ${ }^{22,27,28}$ Regardless of the measure used, the mean effect size for empathic interventions is small to medium. ${ }^{22,29-32}$ Attitude changes are infrequent and relatively small as well. ${ }^{20}$ Both the factors associated with efficacy and the small effect sizes overall suggest the importance of childhood socialization.

\section{Socialization Influences}

Empathy development during adolescence is considered crucial. Increases in perspective-taking (cognitive empathy) occur in adolescence, although the pattern of changes in empathic concern (affective empathy) is less clear. Longitudinal studies show mid-adolescence as a time of empathic malleability. ${ }^{33}$ Both cognitive and emotional components of empathy contribute to the development of moral judgment for as perspective-taking and empathic skills increase; moral judgment increases too. ${ }^{34}$ Empathy levels and the change in adolescent empathy predicts differences in adulthood social competencies. ${ }^{35}$ After the conclusion of adolescence, empathic capacity (cognitive and affective empathy) remains relatively stable. ${ }^{36,37}$

Socialization during childhood imparts values and social tendencies ${ }^{38,39}$ that persist and guide behavior throughout life - even after one's education, decades of experience and life circumstances have changed. ${ }^{40,41}$ Biographical experiences and personality traits also influence the development and expression of empathy for a lifetime. $^{42,43}$ In particular, results show that prejudice expressed by parents or peers exerts a significant negative impact on a child's empathy over time, whereas intergroup friendships may protect against these declines. ${ }^{44}$ Meaningful diverse friendships during the important adolescent period of empathic malleability may be associated with greater empathy and inclusion. ${ }^{33,45}$ As a result, medical students have a variety of attitudes and dispositions about the value of empathy, the importance of its instruction, ${ }^{25,46}$ and its relationship to desired outcomes. If adequate levels of empathy do not develop during the critical period of adolescent empathy development, ${ }^{35}$ educators must overcome now-embedded genetic, biographical, and attitudinal inhibitors through group instruction five to ten years later. ${ }^{47}$ While some will prove receptive to changing attitudes through teaching, ${ }^{48}$ many physicians-like many Americans may continue to discriminate against those they perceive as different due to the influence of biographical experiences, cultural learnings, or personality traits. ${ }^{49,50}$ A key challenge for educators is distinguishing these responsive and non-responsive populations.

\section{Empathy Measurements}

Such distinctions are especially difficult due to the tendency of conflicting results to arise when testing empathic measures in the same population. This may range from a differing effect size to an outright negative result. ${ }^{30}$ 
These potential discrepancies reflect differing empathic constructs. $^{22,32,51,52}$ Whether these constructs are mutually exclusive, the degree they overlap, or their clinical relevance is all unknown. This is all before considering the issue of patient-to-patient variability in clinical performance which implies accurate assessment requires multiple observations across different clinical settings by different observers. ${ }^{53}$ Considering the case of patients from marginalized populations the issues are more complex still. Some have gone so far as to even argue that the measurement of individual empathy is unknowable. ${ }^{54}$

The uncertainties around educational interventions to promote empathy only expand with a longer frame of reference. According to recent reviews, many interventions have only shown temporary effectiveness. ${ }^{17,19}$ Many of the reported positive short-term studies do not exclude the possible influence of a Hawthorne effect. When longitudinal designs were employed, effect sizes declined over time. ${ }^{29}$ However, the concerns that inspired these curricular innovations were all tied to a negative impact on the quality and character of clinical medicine. While short term efficacy is necessary, it is insufficient to address the problem unless its positive effects are sustained. We educate students to enhance and retain empathic knowledge and skills, not for 6 weeks or even 6 months, but a practice lifetime, 40 years. Given the majority of the empathic instruction occurs early, teachings that lack the durability of a year are likely to have dissipated before the principle clinical exposure. The issue is magnified by the opportunity costs of ineffective instruction. Medical school curriculum committees struggle to meet the demands of various groups to add or increase the time allocated to their pet interest. We, therefore, sought to understand whether the effectiveness of reported studies is maintained over time, whether student characteristics influence long-term efficacy, and if specific types of intervention are more effective than others.

\section{Methodology}

The team discussed important keywords and preferred database vocabulary to develop a search strategy (See Appendix A). Databases searched included PubMed, Cochrane, Embase, CINAHL, PsycInfo, and Web of Science. The search strategy was adjusted to include the database's preferred vocabulary. Finally, the search was limited to includes studies published from 1980-2019. Relevant articles falling outside of this publication range (e.g. Poole $1980)^{29}$ were added by co-authors.
The time range of publications varied to include articles retrieved from the literature and articles located by other means and included in this study. As we have noted, our central questions were to determine the long-term (defined as greater than 1 year) empathic effectiveness of reported studies by the different types of empathic interventions, and student and school characteristics. After reviewing full-text articles, the Yale MESH Analyzer tool, ${ }^{55}$ which is a website that uses PubMed Identification numbers to retrieve MESH terms for published articles, was used to verify that the selected articles matched the inclusion and exclusion criteria of the study.

\section{Inclusion Criteria}

Our inclusion criteria specified peer-reviewed studies of medical trainees published in the English language. Empathy had to be quantitatively measured before and following an empathic intervention with a pre-specified follow-up period and an appropriate statistical analysis. When empathic improvement was not the primary focus of the study, but valid measures of empathy were employed on an appropriate population, the study results were included. Philosophical, theoretical, qualitative, single case studies and correlational articles were excluded.

\section{Study Methodological Quality}

The methodological quality (internal consistency, interrater and intra-rater reliability, and criterion validity) was determined using the 10-item medical education research study quality instrument (MERSQI). Studies were independently rated using criteria articulated as adapted from Reed and colleagues. ${ }^{56}$ Study design, sampling, type of data, the validity of the evaluation instrument, data analysis, and outcomes were assessed for each study. Achievable scores ranged from 3-18. Two reviewers independently assessed the study quality of studies meeting study inclusion criteria. Disagreements were resolved by discussion between the reviewers. All meeting the MERSQI quality standard (>7) were included.

\section{Results}

A total of 4910 articles were identified. After 228 duplicates were removed 4682 articles remained (Figure 1). A comprehensive review of all 4682 non-duplicative abstracts and titles was undertaken independently by two co-authors (RFB and MH). When differences arose between reviewers those articles were included in the full- 


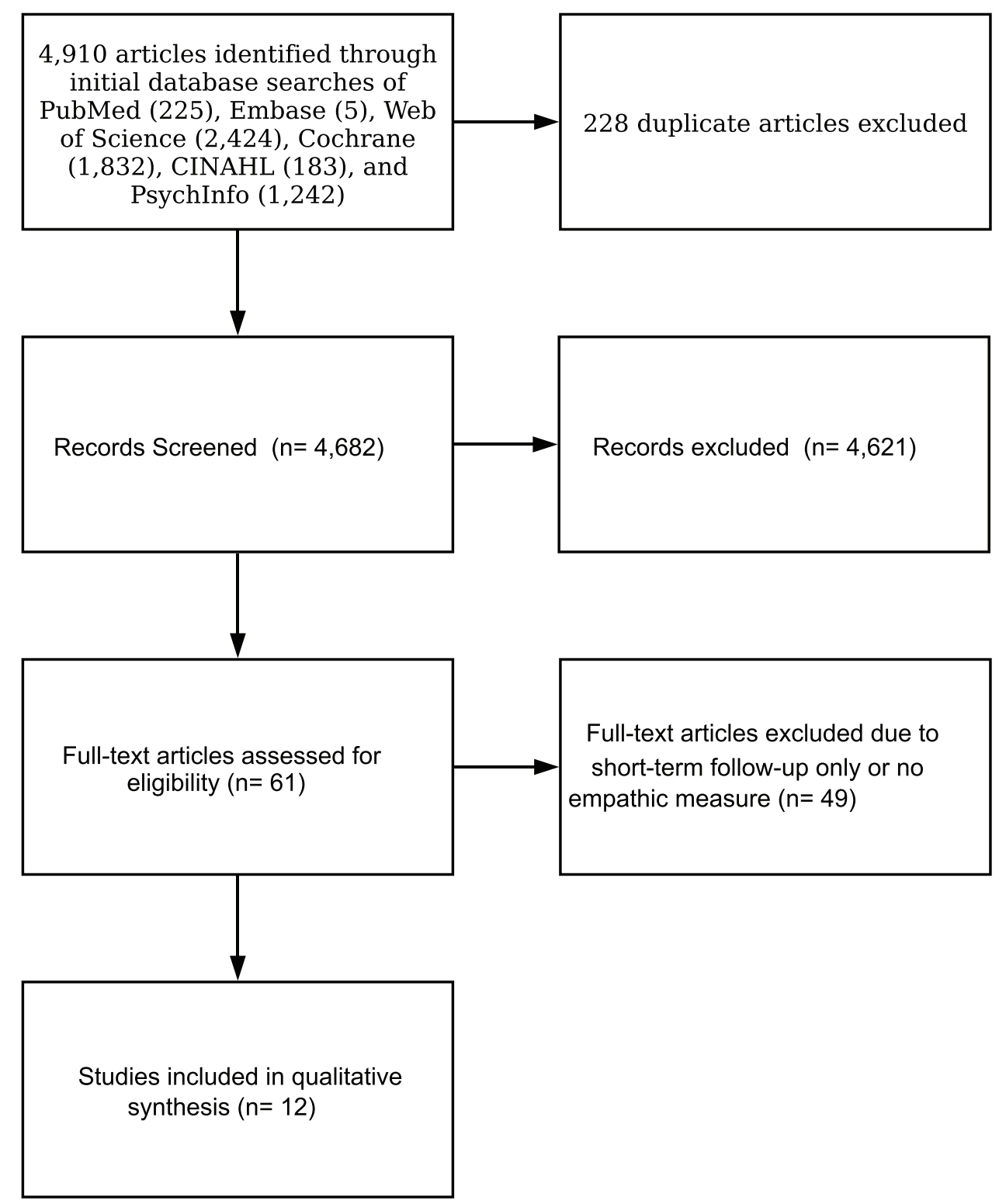

Figure I Flow chart for the inclusion of studies for systematic review.

Note: Adapted from Moher D, Liberati A, Tetzlaff J, Altman DG, The PRISMA Group (2009). Preferred Reporting Items for Systematic Reviews and Meta-Analyses: The PRISMA Statement. PLoS Med 6(7): el000097.

text review. All full-text articles were then screened against the eligibility criteria. The two co-authors selected 61 articles for full-text review. To be inclusive, an additional ten potential articles were identified by a review of the reference section of recent publications. The range of MERSQI scores for accepted articles was 7.5 to 10 . The median score was 8 . Applying the criteria proposed by Fontaine and colleagues to the MERSQI scores, ${ }^{57}$ all studies were of low quality. According to Kirkpatrick's model of evaluation, ${ }^{58}$ all studies save one were targeted to level 2, learning, while a single study assessed at the level of behavioral change.
The overall number of long-term studies was low, especially when compared to the number and diversity of shortterm investigations ${ }^{16,26,51,52,59-66}$ No two interventions were identical. A majority of the studies were observational cohorts. These tests the gestalt effects of exposure to medical education, where a variety of formal curricula around empathy have been implemented in recent decades, and significant socialization around emotional responses has been noted since the 1960s. ${ }^{67}$ Descriptions of the participants were incomplete or absent. The context was rarely described beyond the study site, without specific characterization of each school's curriculum or empathy-related didactics. No 
study described their institution's broader climate or the nature of its hidden curriculum. Collectively, these issues are important because they provide a framework for understanding the effectiveness of educational interventions.

Five articles were from the US and seven from abroad. US studies show declines over time. New Zealand, Japanese, and English studies using the Jefferson Scale of Physician Empathy (JSPE) scores in their respective language versions declined over the years as well (Figure 2). A single UK study using the Interpersonal Reactivity Index (IRI) found mixed results. Different measures of cognitive empathy either increased or decreased over time within the same study population depending on the study instrument utilized. ${ }^{51}$ Differences in culture, educational system, population, and other differences preclude direct comparisons with studies from other countries, yet the absence of any consistent, lasting improvement in essentially every study is a disappointment.

\section{Discussion}

We conducted a review of the English language literature for long term outcomes of empathy training in medical education (Table 1). This focus was selected because the challenge for any intervention to change empathy is not only overcome the unconscious and conscious nature of empathy but also inculcate a level of change that is automatic at a state level and insulated over time in an enduring way. ${ }^{68}$ We identified twelve articles meeting criteria for inclusion, which collectively offered little evidence for the proposition that educational interventions improve the empathy of medical trainees. While overall evidence is sparse, important themes emerged including the measurement of empathy, the impact of clinical exposure, and the importance of baseline disposition.

The complexity of measuring empathy emerged as a major concern in our review. Not only did instruments vary across studies, but the underlying construct of empathy employed varied as well. Which, if any construct is best at measuring clinically meaningful attributes of empathy, remains to be elucidated. Both the Interpersonal and Social Empathy Index and the Questionnaire of Cognitive and Affective Empathy have been validated for use in the general population. ${ }^{69,70}$ There has been limited application of these instruments to healthcare-specific contexts. The IRI is amongst the most widely used measures of empathy in the general population and has been validated for use within healthcare contexts. ${ }^{71}$ However, the version employed by Quince et $\mathrm{al}^{62}$ is modified to present only two subscales, reflecting only half the factors originally described. ${ }^{37}$ While popular, recent scholarship has challenged the validity of some twofactor structures. ${ }^{72}$ To our knowledge, there has been no specific validation of the modified version employed here, meriting caution in our interpretation of the results. The majority of studies employed the JSPE. This self-report survey was developed explicitly for and has been validated in healthcare providers. ${ }^{73}$

\section{Mean Change in JSPE Score Over Study Period}

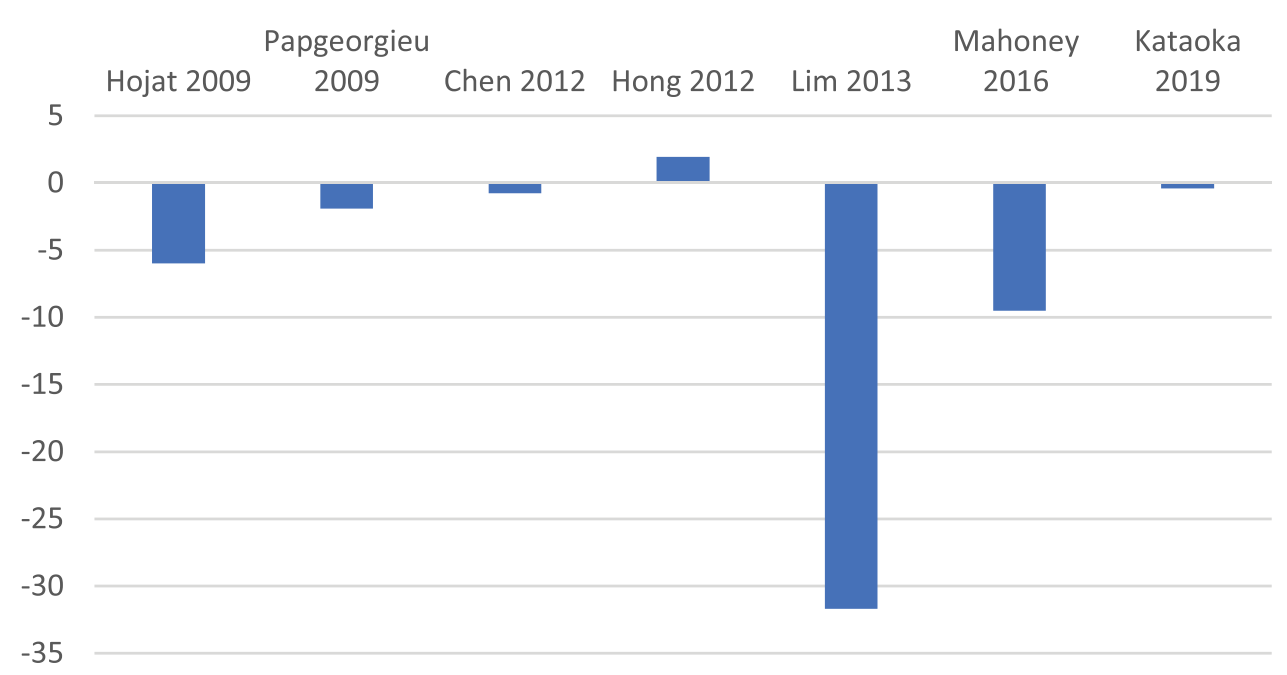

Figure 2 Mean change in JSPE score from first to last measurement in every study. Y-axis is change in score. Studies not utilizing the JSPE and those reporting likelihood ratios excluded. Primary data for calculating standard deviations was not available for all studies and was consequently omitted. 
Table I Selected Features of Studies Analyzed

\begin{tabular}{|c|c|c|c|c|c|c|c|}
\hline Study & $\mathbf{N}$ & Site & Duration & Intervention & Instrument & $\begin{array}{l}\text { Change in } \\
\text { Empathy }\end{array}$ & Outcome \\
\hline $\begin{array}{l}\text { Kataoka } \\
2019^{65}\end{array}$ & 69 & $\begin{array}{l}\text { Single } \\
\text { center } \\
\text { Japan }\end{array}$ & 6 years & Standard curriculum & JSE & -0.4 & No change \\
\hline $\operatorname{Lim} 2013^{60}$ & 72 & $\begin{array}{l}\text { Single } \\
\text { center New } \\
\text { Zealand }\end{array}$ & I year & Standard curriculum & JSE & -0.36 & Decline \\
\hline $\begin{array}{l}\text { Quince } \\
2011^{62}\end{array}$ & & $\begin{array}{l}\text { Single } \\
\text { center UK }\end{array}$ & 4 year & Standard curriculum & $\begin{array}{l}\text { Interpersonal } \\
\text { Reactivity } \\
\text { Index }\end{array}$ & & $\begin{array}{l}\text { No clinically significant } \\
\text { change }\end{array}$ \\
\hline $\begin{array}{l}\text { Hojat } \\
2009^{26}\end{array}$ & 456 & $\begin{array}{l}\text { Single } \\
\text { center US }\end{array}$ & 4 year & Standard curriculum & JSE & -6.0 & Decline \\
\hline $\begin{array}{l}\text { Papageorgiu } \\
2019^{59}\end{array}$ & 66 & $\begin{array}{l}\text { Single } \\
\text { center }\end{array}$ & 5 year & $\begin{array}{l}\text { Standard curriculum/ } \\
\text { Annual communications } \\
\text { skill session }\end{array}$ & JSE & -1.9 & Decline \\
\hline $\begin{array}{l}\text { Smith } \\
2017^{51}\end{array}$ & 129 & $\begin{array}{l}\text { Multi- } \\
\text { center } \\
\text { Chicago IL }\end{array}$ & 3 year & Standard curriculum & $\begin{array}{l}\text { JSE-Student } \\
\text { version + } \\
\text { QCAE }\end{array}$ & $\begin{array}{l}-0.09 /(\mathrm{mo} ?) \\
\text { (JSPE) } \\
/\end{array}$ & Decline \\
\hline $\begin{array}{l}\text { Wellbery } \\
2019^{64}\end{array}$ & 76 & $\begin{array}{l}\text { Single } \\
\text { center US }\end{array}$ & 3 year & Standard curriculum & $\begin{array}{l}\text { Social } \\
\text { Empathy } \\
\text { Index }\end{array}$ & +0.19 & Improve \\
\hline $\begin{array}{l}\text { Mahoney } \\
2016^{63}\end{array}$ & 281 & $\begin{array}{l}\text { Single } \\
\text { Center } \\
\text { Australia }\end{array}$ & I year & Standard curriculum & JSE & -9.5 & Decline \\
\hline $\begin{array}{l}\text { Poole } \\
1980^{29}\end{array}$ & 45 & $\begin{array}{l}\text { Single } \\
\text { Center } \\
\text { Australia }\end{array}$ & 3 year & $\begin{array}{l}\text { Tune-In Empathy Training } \\
\text { Workshop }\end{array}$ & $\begin{array}{l}\text { Accurate } \\
\text { Empathy Scale }\end{array}$ & $\begin{array}{l}+0.91 \text { in } \\
\text { experimental } \\
\text { group }\end{array}$ & Improve \\
\hline $\begin{array}{l}\text { Hong } \\
2012^{61}\end{array}$ & 233 & $\begin{array}{l}\text { Single } \\
\text { Center } \\
\text { Korea }\end{array}$ & I year & $\begin{array}{l}\text { Standard curriculum, MC } \\
\text { vs MS system }\end{array}$ & JSE & +1.95 & Improve \\
\hline Chen $2012^{16}$ & 1162 & $\begin{array}{l}\text { Multi- } \\
\text { center US }\end{array}$ & 4 year & Standard curriculum & JSE & -0.76 & Decline \\
\hline $\begin{array}{l}\text { Hojat } \\
2005^{66}\end{array}$ & & & & & JSE & & $\begin{array}{l}\text { This doesn't seem to } \\
\text { measure change in empathy } \\
\text { over time }\end{array}$ \\
\hline
\end{tabular}

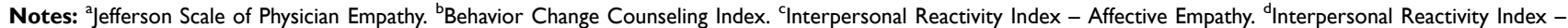

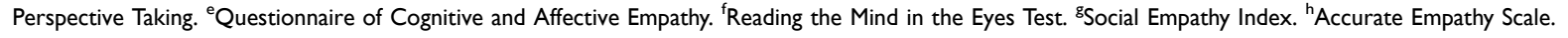

Even here there are caveats. While it measures both affective and cognitive aspects of empathy, the conceptualization of the JSPE was oriented primarily to the latter. ${ }^{74}$ Such models do not account well for the gap that can emerge between knowledge and behavior in clinical medicine. This phenomenon has been amply demonstrated even in cases much simpler and more robustly supported than empathy. ${ }^{75}$ At present, a small number of studies suggests a correlation between high JSPE scores and long-term behavior ${ }^{66}$ or outcomes. ${ }^{76}$ Summarily while no single instrument demonstrated all ideal qualities for measuring empathy, the studies using the best widely-available tools for measurement demonstrated a trend towards decline. 


\section{Teaching May Not Be the Answer}

Only one study stratified participants according to their baseline level of empathy. In it, the participants with the highest initial scores recorded the least longitudinal declines. ${ }^{16}$ Nine studies stratified by gender and all found female participants had higher baseline empathy scores. Among these, one noted a greater rate of increase in empathy in females than males ${ }^{64}$ one reported a smaller decline in females than males, ${ }^{26}$ one reported a trend towards a slower rate of decline in females ${ }^{59}$ and another had a similarly suggestive phenomenon amongst third year students wherein, while initial differences were not statistically significant, in serial testing such a gender gap opened despite declines in both groups. ${ }^{63}$ The remainder that commented reported no difference in the rate of change by gender. ${ }^{6,16,51,60,61}$ Cumulatively, these results suggest the importance of a student's baseline empathic disposition on entering medical school. Regardless of the achieved changes in empathy with instruction, this suggests one alternative for addressing deficits currently observed in medical education. In current admissions practice, medical students reflect the complete spectrum of empathic dispositions. ${ }^{77-79}$ Applying more discretion around the selection of students with demonstrable records of prosocial activities with diverse groups may be helpful. At present, it is better supported than attempts to "teach" learners out of their base empathic predispositions. It also balances respect for the autonomy of those who chose little interest in empathy on the one hand, and more assuredly limiting the resultant compromises in quality of care that might derive from the current practice of directing them towards technology-oriented specialties ${ }^{80}$ on the other.

\section{Clinical Interactions are Not Enough}

The most common exposure in the reviewed literature was to the existing curriculum. The majority of these studies demonstrated declines in empathy. This is uniformly true in those studies conducted in locales like Chicago and Philadelphia, where ethnic and economic diversity is above the mean for American cities. ${ }^{81}$ This finding is also congruent with previous reports that the greatest declines in empathy occur during the clinical years of training. ${ }^{26}$ While brief interactions between learners and marginalized populations occur all the time in medicine, research suggests such contacts do little for students' greater understanding of marginalized people. ${ }^{82}$ The idea that merely being present while "good" medicine takes place is not an effective learning strategy because student learning from role models is complex and haphazard. ${ }^{83}$ Empathic, inclusive attitudes are associated with having experienced diverse interactions of varying levels of intimacy bolstered by everyday instances of proximity and familiarity, ${ }^{84}$ not just structured clinical activity. ${ }^{85}$

\section{Change is Possible}

However, empathy can be augmented in receptive subjects. ${ }^{86,87}$ In contrast to the interventions reported here, those that successfully change traits are often more intense and individualized. They last an average of five days/week for 24 weeks, ${ }^{88}$ which is much longer and more intense than that typically reported for medical school group empathic interventions. The implicit attitudes that foster the development of an empathic physician can be developed over a long period of repeated exposure that overcomes the natural resistance to change. ${ }^{89}$ Repeated short-term, situational processes are necessary cumulatively for lasting changes in explicit and implicit personality characteristics and behavioral patterns as well as long-term personality change. ${ }^{90}$ The changes most associated with improved self-rated preparedness to care for diverse patient populations include increased dispositional empathy, reduced social dominance orientation, and reduced need for cognitive closure. ${ }^{20,91}$ However, this development requires conditions that are difficult to replicate within a medical school curriculum. There is some parallel in the way everyday interactions can build emotional connections between classmates and faculty, ultimately facilitating inclusiveness and the success of marginalized students. ${ }^{92,93}$

\section{A Hypothesis on Clinical Exposure and Declining Empathy}

An intriguing possibility is that the observed declines in clinical empathy are not a loss of overall empathic capacity at all, but rather a lack of use within the physician-patient interaction. ${ }^{25}$ If true, it suggests the issue is empathic motivation. The many efforts targeting affective and cognitive elements may be misdirected. The ability to perceive and be sensitive to the emotional states of others must be coupled with the motivation to care for their wellbeing. All three facets of empathy (affective, cognitive, and motivational) are important and must be engaged and adapted to positively influence patients' health. ${ }^{3}$ Empathy declines until a "minimum level of empathy" that meets personal and professional needs is established. ${ }^{94}$ Several lines of evidence support this possibility. Recent neuroscientific studies show that "mirror neurons" enable us to empathize with others, ${ }^{95}$ setting the stage for empathic expression. But the signal rate of these neurons is substantially reduced when a person with 
limited empathic capacity experiences anxiety, tension, or distress. The conflict between the social expectation of empathy for patients with a given social identity and the provider's beliefs about them creates exactly such conditions. Students detach and distance themselves from patients during the course of medical instruction ${ }^{96}$ until some personal compromise is reached that minimally satisfies personal and professional expectations and personal comfort level. Whether the frequency or duration of empathy-inducing exposure associated factors or some combination causes the cognitive adjustment is unknown. The observation that students with lower baseline empathy at the start of medical school have a faster rate of decline and decreased further than those with higher baseline empathy ${ }^{16}$ is in line with this theory. Students with lower empathy scores self-select technology-oriented specialties, perhaps because they recognize their inherent limitations with empathic encounters. ${ }^{16}$ Moreover, the theory also offers a plausible rationale for the linkages between empathy, depression, and burnout as manifestations of incongruence between personal and professional expectations, clinical practice, and personal comfort level.

\section{Future Research Improvements}

Methodological weaknesses have been heralded by many authors as an important shortcoming of this body of investigation. This review found little has changed. Improvements are possible. A greater number of long-range studies reporting results beyond one year should be undertaken. Greater specificity should be encouraged about the nature of interventions and the program of instruction as it relates to empathy. Careful, broad appraisal of the context of instruction is necessary. Reported success or failure may be influenced by extrinsic factors like the overall diversity climate or hidden curriculum of the institution. Short of this, more meaningful characterization of the school like size, class composition, location, and mission would provide important context. Especially when undertaking long term studies, current theories for decline in empathy make these kinds of descriptors essential. Authors should also consider employing multiple relational empathic tools and identify which area of empathic is under investigation: behavior, attitude, or orientation.

Both the entire body of results suggesting the stability of empathic trajectories and the findings stratified by empathy suggest an important new direction for research. While study size is an understandable limitation, the general trend has instead been towards judging aggregate movement of the class without consideration of movement by subpopulations (e.g., high vs. low empathy groups or greater vs. lower racial implicit bias). ${ }^{97}$ Those in the lowest strata of measured empathy deserve special attention. What happens to the average student following an empathic intervention may have less salience if lowertier students fail to improve or get worse. ${ }^{20,98}$ These issues may have particular relevance since those who have lower scores get even worse with clinical exposure. ${ }^{16}$ It is unclear what to do with students exhibiting these characteristics because empathic motivation may be lacking for just specific populations, a condition that is seldom examined. An explicit assessment of student expectations and desires also seems warranted. Understandably, the effectiveness of the empathic training may have little - or even an adverse - effect on students with little interest, low empathic capacity, or in schools where the context for learning is poor. ${ }^{20,99} \mathrm{By}$ considering stratified rather than aggregate outcomes alone, effective interventions might be identified in the receptive group, while important backlash effects could be identified among those that are not interested or have low baseline empathy.

Finally, the practical dimension of the proposed interventions deserves greater scrutiny. As a statistically significant result does not guarantee clinically important improvement, let alone gains sufficient for empathic adequacy or competency to practice medicine, studies focused on later stages of change would be helpful. ${ }^{9}$ Implementation costs to students must roughly reflect the value and expectation that they place on achieving greater empathy and the benefits they believe it will bring. Performing new behaviors or having new experiences must be made feasible and socially desirable within the students' social environment. ${ }^{59,100}$ Resistance to empathy messaging and or even a backlash can occur with poorly targeted or executed interventions.

\section{Limitations}

We accepted the results published in all papers that measured empathic interventions with follow-up at face value. Cognitive empathy was most often explored. Many interventions were short-term, single-institution studies that were pilot or preliminary studies. Descriptions about the participants or context were most often missing or incomplete. Most often the concept being investigated was not well described. The lack of demonstrated effectiveness of our current efforts does not mean that "teaching empathy" could not or does not ever work. The results could be due to the low power of studies, unique sample characteristics, the medical school context, procedural details other than the intervention itself, or there could be yet unidentified 
constraints for when interventions will be useful. Additional empathic research is warranted.

\section{Conclusions}

Disturbingly, despite 20 years of "teaching empathy," that challenge of teaching empathy has not been met. Demonstrable evidence for empathic improvement following empathic interventions consists primarily of positive, shortterm results using a variety of methodologies. Programs have been presumed valid and to result in better patient care with merely preliminary results. But based on the available evidence, there is very little support for any lasting effect of any empathic intervention regardless of what instrument is used to measure it or how it was taught. The relational themes that guide medical students with greater humanism appear enduring $^{60,101}$ but seldom acquired by those exhibiting less humanism. $^{61}$

Increasing public dissatisfaction with physicians, 40 years of declining empathy among US college students, measurable declines in empathy as a result of medical education and training, and the inability to demonstrably prove that empathy can be taught or maintained long-term cannot be ignored. The development of an effective relational empathy pedagogy needs to become a focus of medical education. ${ }^{5}$ The learning environment at more than sixty percent of American medical schools is hostile to learners with a pro-social orientation. ${ }^{88}$ Corrective action should be pursued in a multi-modal fashion. The role of the hidden curriculum ${ }^{102}$ in undoing the strides made by earlier empathy instruction is under-studied relative to the exploration of factors promoting empathy. This research could be paired with more decisive action to resolve these noxious influences. Tackling these and other inhibitors of empathy $^{103}$ would do much to improve the educational climate.

To tilt the composition of medical schools towards empathy, selection processes should be redesigned to favor both faculty and student candidates with correlates of high empathy, like a sustained history of prosocial activities, ${ }^{103-105}$ and a favorable profile of noncognitive abilities. ${ }^{106-108}$ Designing the selection process to favor individuals with higher empathy initially may result in greater empathy upon graduation ${ }^{109}$ and potentially beyond. ${ }^{79}$ The choice in medical school selection is not a Faustian choice of either/or as applicants display a spectrum of both cognitive and noncognitive characteristics including empathy. A holistic review of the thousands of academically capable students possessing the desired personal attributes should be favored over those lacking the requisite empathic qualities. The case for action is straightforward. If patients are truly valued as equals, faults in empathic behavior need not occur. ${ }^{110}$ This is a mandate for institutional change, not merely curriculum reform. While we attempt wellevidenced interventions to promote empathy, we cannot and should not ignore alternative paths to this goal.

\section{Acknowledgments}

The authors would like to acknowledge the thoughtful suggestions by BCB and MTS on earlier drafts of the manuscript.

\section{Funding}

There is no funding to report.

\section{Disclosure}

The authors report no conflicts of interest in this work.

Disclaimer: The views expressed in the manuscript solely reflect the views of the authors.

Prior presentations: None

\section{References}

1. Kirch DG Core competencies and the heart of learning. AAMCNews. Available from: https://news.aamc.org/medicaleducation/article/word-president-core-competencies-and-heartlearnin/. Accessed September 26, 2017.

2. Association of American Medical Colleges. Core entrustable professional activities for entering residency. 2017. Available from: https://www.aamc.org/download/484778/data/epa13toolkit.pdf. Accessed November 11, 2018.

3. Decety J, Fotopoulou A. Why empathy has a beneficial impact on others in medicine: unifying theories. Front Behav Neurosci. 2015;8:457. doi:10.3389/fnbeh.2014.00457

4. Abreu BC. Accentuate the positive: reflections on empathic interpersonal interactions. Am J Occ Ther. 2011;65(6):623-634. doi:10.5014/ajot.2011.656002

5. Sulzer SH, Feinstein NW, Wendland CL. Assessing empathy development in medical education: a systematic review. Med Educ. 2016;50(3):300-310. doi:10.1111/medu.12806

6. Quince T, Thiemann P, Benson J, Hyde S. Undergraduate medical students' empathy: current perspectives. Adv Med Educ Pract. 2016;7:443-455. doi:10.2147/AMEP.S76800

7. Heinrich J, Heine SJ, Norenzayan A. The weirdest people in the world? Behav Brain Sci. 2010;33:61-83. doi:10.1017/ S0140525X0999152X

8. Wright B, McKendree J, Morgan L, Allgar VL, Brown A. Examiner and simulated patient ratings of empathy in medical student final year clinical examination: are they useful? BMC Med Educ. 2014;14:1-8.

9. Hojat M, Gonnella JS, Mangione S, et al. Empathy in medical students as related to academic performance, clinical competence and gender. Med Educ. 2002;36(6):522-527. doi:10.1046/j.13652923.2002.01234.x

10. Ogle J, Bushnell JA, Caputi P. Empathy is related to clinical competence in medical care. Med Educ. 2013;47(8):824-831. doi:10.1111/medu.12232

11. Konrath SH, O'Brien EH, Hsing C. Changes in dispositional empathy in American college students over time: meta analysis. Pers Soc Psychol Rev. 2011;15(2):180-198. doi:10.1177/ 1088868310377395 
12. Twenge JM, Campbell SM. Generational differences in psychological traits and their impact on the workplace. J Man Psychol. 2008;23(8):862-877. doi:10.1108/02683940810904367

13. Li J, Dow WH, Kariv S. Social preferences of future physicians. PNAS. 2017;114(48):E10291-E10300. doi:10.1073/pnas.17054511 14

14. Konrath SH, Chopik WJ, Hsing CK, O’Brien E. Changes in adult attachment styles in American college students over time: a meta-analysis. Pers Soc Psychol Rev. 2014;18(4):326-348. doi:10.1177/1088868314530516

15. Sheehan KH, Sheehan DV, White K, Leibowitz A, Baldwin DC Jr. A pilot student of medical student "abuse": student perceptions of mistreatment and misconduct in medical school. JAMA. 1990;263:533-537. doi:10.1001/jama.1990.03440040072031

16. Chen DCR, Kirshenbaum DS, Yan J, Kirshenbaum E, Aseltine RH. Characterizing changes in student empathy throughout medical school. Med Teach. 2012;34(4):305-311. doi:10.3109/0142159X.2012.644600

17. Pedersen R. Empathy development in medical education-A critical review. Med Teach. 2010;32:593-600. doi:10.3109/ 01421590903544702

18. Association of American Medical Colleges. Learning objectives for medical student education: guidelines for medical schools. 1998. now incorporated in core entrustable professional activities for entering. Residency. AAMC. Core entrustable professional activities for entering residency. Available from: https://www. aamc.org/initiatives/coreepas. Accessed January 7, 2018.

19. Kelm Z, Womer J, Walter JK, Feudtner C. Interventions to cultivate physician empathy: a systematic review. BMC Med Educ. 2014;14:219. doi:10.1186/1472-6920-14-219

20. Meadows A, Higgs S, Burke SE, Dovidio JF, van Ryan M, Phelan SM. Social dominance orientation, dispositional empathy, and need for cognitive closure moderate the impact of empathyskills training, but not patient contact, on medical students' negative attitudes toward higher-weight patients. Front Psychol. 2017;8:504. doi:10.3389/fpsyg.2017.00504

21. Bunn W, Terpstra J. Cultivating empathy for the mentally ill using simulated auditory hallucinations. Acad Psychiatry. 2009;33 (6):457-460. doi:10.1176/appi.ap.33.6.457

22. Shapiro J, Morrison E, Boker J. Teaching empathy to first year medical students: evaluation of an elective literature and medicine course. Educ Health (Abingdon). 2004;17(1):73-84. doi:10.1080/ 13576280310001656196

23. Rosenthal S, Howard B, Schlussel YR, et al. Humanism at heart: preserving empathy in third-year medical students. Acad Med. 2011;86(3):350-358. doi:10.1097/ACM.0b013e318209897f

24. Bombeke K, Van Roosbroeck S, De Winter B, et al. Medical students trained in communication skills show a decline in patient-centered attitudes: an observational study comparing two cohorts during clinical clerkships. Patient Educ Couns. 2011;84:310-318. doi:10.1016/j.pec.2011.03.007

25. van Ryan M, Hardeman RR, Phelan SM, et al. Psychosocial predictors of attitudes toward physician empathy in clinical encounters among 4732 1st year medical students: a report from the CHANGES study. Patient Educ Coun. 2014;96(3):367-375. doi:10.1016/j.pec.2014.06.009

26. Hojat M, Vergare MJ, Maxwell K, et al. The devil is in the third year: a longitudinal study of erosion of empathy in medical school. Acad Med. 2009;84(9):1182-1191. doi:10.1097/ ACM.0b013e3181b17e55

27. Lonie JM, Alemam R, Dhing $\mathrm{C}$, et al. Assessing pharmacy student self-reported empathic tendencies. Am J Pharm Educ. 2005;69(2):198-203. doi:10.5688/aj690229

28. Batt-Rawden S, Chisolm MS, Anton B, Flickinger TE. Teaching empathy to medical students: an updated, systematic review. Acad Med. 2013;88(8):1171-1177. doi:10.1097/ACM.0b013e318299f3e3
29. Poole AD, Sanson-Fisher RW. Long-term effects of empathy training on the interview skills of medical students. Patient Couns Health Educ. 1980;2:125-127. doi:10.1016/S0738-3991(80)80053-X

30. Evans BJ, Stanley RO, Burrows GD. Measuring medical students' empathy skills. Br J Med Psychol. 1993;66:121-133. doi:10.1111/j.2044-8341.1993.tb01735.x

31. DiLalla LF, Hull SK, Dorsey JK. Effect of gender, age, and relevant course work on attitudes toward empathy, patient spirituality, and physician wellness. Teach Learn Med. 2004;16 (2):165-170. doi:10.1207/s15328015tlm1602_8

32. Du Vaure B, Lemogne C, Bunge L, et al. Promoting empathy among medical students: a two-site randomized controlled study. J Psychosom Res. 2017;103:102-107. doi:10.1016/j. jpsychores.2017.10.008

33. Miklikowska M. Empathy trumps prejudice: the longitudinal relation between empathy and anti-immigrant attitudes in adolescence. Dev Psychol. 2018;54(4):703-717. doi:10.1037/ dev0000474

34. Rest JR, Narvaez D. The college experience and moral development. In: Kurtines WM, Gewirtz JL, editors. Handbook of Moral Behavior and Development Volume 2: Research. Hillsdale, NJ: Lawrence Erlbaum; 1991:229-245.

35. Allemand M, Steiger AE, Fend HA. Empathy development in adolescence predicts social competencies in adulthood. J Pers. 2015;83(2):229-241. doi:10.1111/jopy.12098

36. Eisenberg N, Fabes RA. Empathy: conceptualization, measurement, and relation to prosocial behavior. Motiv Emot. 1990;14:131-149. doi:10.1007/BF00991640

37. Davis MH. Measuring individual differences in empathy: evidence for a multidimensional approach. J Pers Soc Psychol. 1983;44:113-126. doi:10.1037/0022-3514.44.1.113

38. Schein EH. The individual, the organization, and the career: a conceptual scheme. J App Behav Sci. 1971;7:401-426. doi:10.1177/002188637100700401

39. Lutfey K, Mortimer JT. Development and socialization through the adult life course. In: Delamater J, editor. Handbook of Social Psychology. Boston: Springer; 2006:183-202.

40. Kish-Gephart J, Campbell JT. You don't forget your roots: the influence of CEO social class background on strategic risk taking. Acad Man J. 2015;58:1614-1636. doi:10.5465/amj.2013.1204

41. Martin SR, Cote S, Woodruff T. Echoes of our up-bringing: how growing up wealthy or poor relates to narcissism, leader behavior, and leader effectiveness. Acad Man J. 2016;59:2157-2177. doi:10.5465/amj.2015.0680

42. McManus IC, Keeling A, Paice E. Stress, burnout and doctors' attitudes to work are determined by personality and learning style: a twelve-year longitudinal study of UK medical graduates. $B M C$ Med Educ. 2004;2:293.

43. Guilera T, Batalla I, Forné C, Soler-González J. Empathy and big five personality model in medical students and its relationship to gender and specialty preference: a cross sectional study. BMC Med Educ. 2019;19:57. doi:10.1186/s12909-019-1485-2

44. Miklikowska M. Development of anti-immigrant attitudes in adolescence: the role of parents, peers, intergroup friendships, and empathy. Br J Psychol. 2017;108(3):626-648. doi:10.1111/bjop.12236

45. Grütter J, Gasser L, Zuffianò A, Meyer B. Promoting inclusion via cross-group friendship: the mediating role of change in trust and sympathy. Child Dev. 2018;89:e414-e430. doi:10.1111/cdev.12883

46. Dogra N, Karnik N. First-year medical students' attitudes toward diversity and its teaching: an investigation at one US medical school. Acad Med. 2003;78:1191-1200. doi:10.1097/00001888200311000-00023

47. Tackett S, Wright S, Colbert-Getz J, Shochet R. Associations between learning community engagement and burnout, quality of life, and empathy among medical students. Int J Med Educ. 2018;9:316-322. doi:10.5116/ijme.5bef.e834 
48. Hardeman RR, Burgess D, Phelan S, Yeazel M, Nelson D, van Ryn M. Medical student socio-demographic characteristics and attitudes toward patient centered care: do race, socioeconomic status and gender matter? A report from the medical student CHANGES study. Patient Educ Couns. 2015;98(3):350-355. doi:10.1016/j.pec.2014.11.013

49. Dehon E, Weiss N, Jones J, et al. A systematic review of the impact of physician implicit racial bias on clinical decision making. Acad Emerg Med. 2017;24(8):895-904. doi:10.1111/ acem. 13214

50. Han $\mathrm{S}$. Neurocognitive basis of racial ingroup bias in empathy. Trend Cog Sci. 2018;22(5):400-421. doi:10.1016/j.tics.2018.02.013

51. Smith KE, Norman GJ, Decety J. The complexity of empathy during medical school training: evidence for positive changes. Med Educ. 2017;51(11):1146-1159. doi:10.1111/medu.13398

52. Riess H, Kelley JM, Bailey RW, Dunn EJ, Phillips M. Empathy training for resident physicians: a randomized controlled trial of a neuroscience-informed curriculum. J Gen Intern Med. 2012;27 (10):1280-1286. doi:10.1007/s11606-012-2063-z

53. Norcini JJ. Peer assessment of competence. Med Educ. 2003;37 (6):539-543. doi:10.1046/j.1365-2923.2003.01536.x

54. Veen M, Skelton J, de la Croix A. Knowledge, skills and beetles: respecting the privacy of private experiences in medical education. Perspect Med Educ. 2020;9:111-116. doi:10.1007/ s40037-020-00565-5

55. Yale Med MESH Analyzer Tool. Available from: http://mesh. med.yale.edu/. Accessed November 18, 2019.

56. Reed DA, Cook DA, Beckman TJ, Levine RB, Kern DE, Wright SM. Association between funding and quality of published medical education research. JAMA. 2007;298 (9):1002-1009. doi:10.1001/jama.298.9.1002

57. Fontaine G, Cossette S, Maheu-Cadotte M-C, et al. Behavior change counseling training programs for nurses and nursing students: a systematic descriptive review. Nurse Educ Today. 2019;82:37-50. doi:10.1016/j.nedt.2019.08.007

58. Kirkpatrick D. Revisiting Kirkpatrick's four-level model. Train Dev. 1996;1:54-59.

59. Papageorgiou A, Miles S, Fromage M. Does medical students' empathy change during their 5-year MBBS degree? Educ Health. 2018;31:142-147.

60. Lim BT, Moriarty H, Huthwaite M, Gray L, Pullon S, Gallagher P. How well do medical students rate and communicate clinical empathy? Med Teach. 2013;35(2):e946-e951. doi:10.3109/0142159X.2012.715783

61. Hong M, Lee WH, Park JH, et al. Changes of empathy in medical college and medical school students: 1-year follow up study. BMC Med Educ. 2012;12(1):122. doi:10.1186/1472-6920-12-122

62. Quince TA, Parker RA, Wood DF, Benson JA. Stability of empathy among undergraduate medical students: a longitudinal study at one UK medical school. BMC Med Educ. 2011;11(1):90. doi:10.1186/1472-6920-11-90

63. Mahoney S, Sladek RM, Neild T. A longitudinal study of empathy in pre-clinical and clinical medical students and clinical supervisors. BMC Med Educ. 2016;16(1):270. doi:10.1186/ s12909-016-0777-z

64. Wellbery C, Barjasteh T, Korostyshevskiy V. Medical students' individual and social empathy: a follow-up study. Med Teach 2019;41(6):656-661. doi:10.1080/0142159X.2018.1538551

65. Kataoka H, Iwase T, Ogawa H, et al. Can communication skills training improve empathy? A six-year longitudinal study of medical students in Japan. Med Teach. 2019;41(2):195-200. doi:10.1080/0142159X.2018.1460657

66. Hojat M, Mangione S, Nasca S, Nasca TJ, Gonnella JS, Magee M. Empathy scores in medical school and ratings of empathic behavior in residency training 3 years later. $J$ Soc Psychol. 2005;145(6):663-672. doi:10.3200/SOCP.145.6.663-672
67. Lief HI, Fox RC. Training for "detached concern" in medical students. In: HI Lief, VC Lief, NR Lief (Eds.),The Psychological Basis for Medical Practice. 1963:12-35. New York : Harper \& Row.

68. Magidson JF, Roberts BW, Collado-Rodriguez A, Lejuez CW. Theory-driven intervention for changing personality: expectancy value theory, behavioral activation, and conscientiousness. Dev Psychol. 2014;50(5):1442-1450. doi:10.1037/a0030583

69. Lietz CA, Gerdes KE, Sun F, Geiger JM, Wagaman MA, Segal EA. The Empathy Assessment Index (EAI): a confirmatory factor analysis of a multidimensional model of empathy. J Soc Social Work Res. 2011;2(2):104-124. doi:10.5243/jsswr.2011.6

70. Renate LE, Reniers P, Corcoran R, Drake R, Shryane NM, Völlm BA. The QCAE: a questionnaire of cognitive and affective empathy. J Pers Assess. 2011;93(1):84-95. doi:10.1080/ 00223891.2010 .528484

71. Costa P, de Carvalho-filho MA, Schweller M, et al. Measuring medical students' empathy: exploring the underlying constructs of and associations between two widely used self-report instruments in five countries. Acad Med. 2017;92(6):860-867. doi:10.1097/ ACM.0000000000001449

72. Chysikou EG, Thompson WJ. Assessing cognitive and affective empathy through the interpersonal reactivity index: an argument against a two-factor model. Assessment. 2016;23(6):769-777. doi:10.1177/1073191115599055

73. Hojat M. Empathy in Patient Care: Antecedents, Development, Measurement, and Outcomes. New York, NY: Springer; 2007.

74. Hojat M. Empathy in Health Professions Education and Patient Care. New York, NY: Springer International; 2016.

75. Kahlke R, McConnell M, Wisener K, Eva K. The disconnect between knowing and doing in health professions education and practice. Adv Health Sci Educ. 2020;25:227-240. doi:10.1007/ s10459-019-09886-5

76. Hojat M, Louis DZ, Markham FW, Wender R, Rabinowitz C, Gonnella JS. Physicians' empathy and clinical outcomes for diabetic patients. Acad Med. 2011;86:359-364. doi:10.1097/ ACM.0b013e3182086fe1

77. CARE Measure. Available from: http://www.measuringimpact. org/s4-care-measure. Accessed July 31, 2017.

78. Mercer SW, Maxwell M, Heaney D, Watt GC. The consultation and relational empathy (CARE) measure: development and preliminary validation and reliability of an empathy-based consultation process measure. Fam Pract. 2004;21(6):699-705.

79. Hojat M, DeSantis J, Shannon SC, et al. The Jefferson scale of empathy: a nationwide study of measurement properties, underlying components, latent variable structure, and national norms in medical students. Adv Health Sci Edu. 2018;23:899-920. doi:10.1007/s10459-018-9839-9

80. Han JL, Pappas TN. A review of empathy, its importance, and its teaching in surgical training. J Surg Educ. 2018;75(1):88-94. doi:10.1016/j.jsurg.2017.06.035

81. McCann A Most diverse cities in the U.S. Wallet Hub. April 10, 2019. Available from: https://wallethub.com/edu/most-diversecities/12690/.k. Accessed May 29, 2020.

82. Wear D, Kuczewski MG. Medical students' perceptions of the poor: what impact can medical education have? Acad Med. 2008;83(7):639-645. doi:10.1097/ACM.0b013e381782d67

83. Horsburgh J, Ippolito K. A skill to be worked at: using social learning theory to explore the process of learning from role models in clinical settings. BMC Med Educ. 2018;18:156. doi:10.1186/s12909-018-1251-x

84. Dixon JC. The ties that bind and those that don't: toward reconciling group threat and contact theories of prejudice. Soc Forces. 2006;84(4):2179-2204. doi:10.1353/sof.2006.0085 
85. Sherrill WW, Mayo RM, Truong KD, Pribonic AP, Schalkoff CA. Assessing medical student cultural competence: what really matters. Int $J$ Med Educ. 2016;7:248-254. doi:10.5116/ ijme. $578 \mathrm{~b} .687 \mathrm{c}$

86. Ferguson E, Lievens F. Future directions in personality, occupational and medical selection: myths, misunderstandings, measurement, and suggestions. Adv Health Sci Educ Theory Pract. 2017;22(2):387-399. doi:10.1007/s10459-016-9751-0

87. Roberts BW, Luo J, Briley DA, Chow PI, Su R, Hill PL. A systematic review of personality trait change through intervention. Psychol Bull. 2017;143:117-141. doi:10.1037/ bul0000088

88. Allemand M, Flückiger C. Changing personality traits: some considerations from psychotherapy process-outcome research for intervention efforts on intentional personality change. $J$ Psychother Integr. 2017;27(4):476-494. doi:10.1037/int0000094

89. Hardeman RR, Przedworski JM, Burke S, et al. Association between perceived medical school diversity climate and change in depressive symptoms in medical students: a report from the medical student CHANGE study. J Nat Med Assoc. 2016;108 (4):225-235.

90. Wrzus C, Roberts BW. Processes of personality development in adulthood: the TESSERA framework. Per Soc Psychol Rev. 2017;21(3):253-277. doi:10.1177/1088868316652279

91. Niu NN, Syed ZA, Krupat E, et al. The impact of cross-cultural interactions on medical students' preparedness to care for diverse patients. Acad Med. 2012;87(11):1530-1534. doi:10.1097/ ACM.0b013e31826d40f5

92. Leyerzapf H, Abma TA, Steenwijk RR, Croiset G, Verdonk P. Standing out and moving up: performance appraisal of cultural minority physicians. Adv Health Sci Educ Theory Pract. 2015;20 (4):995-1010. doi:10.1007/s10459-014-9577-6

93. van den Brink M, Benschop Y. Gender practices in the construction of academic excellence: sheep with five legs. Organization. 2012;19(4):507-524. doi:10.1177/1350508411414293

94. Gleichgerrcht E, Decety J. The relationship between different facets of empathy, pain perception and compassion fatigue among physicians. Front Behav Neurosci. 2014;8:243.

95. Gallese V. The roots of empathy: the shared manifold hypothesis and the neural basis of intersubjectivity. Psychopathology. 2003;36:171-180. doi:10.1159/000072786

96. Xie J, Yang H, Xia X, Yu S. The influence of medical professional knowledge on empathy for pain: evidence from fNIRS. Front Psychol. 2018;9:1089. doi:10.3389/fpsyg.2018.01089

97. Mana I, Belton T, Ginzberg S, Singh A, Johnson T. A decade of studying implicit racial/ethnic bias in healthcare providers using the implicit association test. Soc Sci Med. 2018;199:219-229. doi:10.1016/j.socscimed.2017.05.009

98. Burgess DJ, Burke SE, Cunningham BA, et al. Medical students' learning orientation regarding interracial interactions affects preparedness to care for minority patients: a report from medical student CHANGES. BMC Med Educ. 2016;16:254. doi:10.1186/ s12909-016-0769-z
99. Phelan SM, Burke SE, Hardeman RR, et al. Medical school factors associated with changes in implicit and explicit bias against gay and lesbian people among 3492 graduating medical students. J Gen Int Med. 2017;32(11):1193-1201. doi:10.1007/ s11606-017-4127-6

100. Chapman BP, Hampson S, Clarkin J. Personality-informed interventions for healthy aging: conclusions from a National Institute on aging work group. Dev Psychol. 2014;50(5):1426-1441. doi:10.1037/a0034135

101. Rutberg PC, King B, Gaufberg E, Brett-MacLean P, Dinardo P, Frankel RM. Do medical students' narrative representations of "the good doctor" change over time? Comparing humanism essays from a national contest in 1999 and 2013. Acad Med. 2017;92:537-543. doi:10.1097/ACM.0000000000001531

102. Eikeland HL, Ørnes K, Finset FA, Pedersen R. The physician's role and empathy - a qualitative study of third year medical students. BMC Med Educ. 2014;14:165. doi:10.1186/1472-6920-14-165

103. Brazeau CM, Schroeder R, Rovi S, Boyd L. Relationship between medical student service and empathy. Acad Med. 2011;86(10 Suppl):S42-S45. doi:10.1097/ACM.0b013e31822a6ae0

104. Schripsema NR, van Trigt AM, van der Wal MA, CohenSchotanus J, Meijer OC. How different medical school selection processes call upon different personality characteristics. PLoS One. 2016;11(3):e0150645. doi:10.1371/journal.pone.0150645

105. de Visser M, Fluit C, Cohen-Schotanus J, Laan R. The effects of a non-cognitive versus cognitive admission procedure within cohorts in one medical school. Adv Health Sci Educ. 2018;23 (1):187-200. doi:10.1007/s10459-017-9782-1

106. Wilson I, Griffin B, Lampe L, et al. Variation in personality traits of medical students between schools of medicine. Med Teach. 2013;35(11):944-948. doi:10.3109/0142159X.2013.827331

107. Haight SJ, Chibnall JT, Schindler DL, Slavin SJ. Associations of medical student personality and health/wellness characteristics with their medical school performance across the curriculum. Acad Med. 2012;87(4):476-485. doi:10.1097/ACM.0b013e318248e9d0

108. Quinlivan JA, Lam LT, Wan SH, Petersen RW. Selecting medical students for academic and attitudinal outcomes in a catholic medical school. Med J Aust. 2010;193(6):347-350. doi:10.5694/ j.1326-5377.2010.tb03947.x

109. Gaufberg E, Dunham L, Krupat E, Stansfield B, Christianson C, Skochelak S. Do gold humanism honor society inductees differ from their peers in empathy, patient-centeredness, tolerance of ambiguity, coping style, and perception of the learning environment? Teach Learn Med. 2018;30(3):284-293. doi:10.1080/10401334.2017.1419873

110. Batson CD, Eklund JH, Chermok VL, Hoyt JL, Ortiz BG. An additional antecedent of empathic concern: valuing the welfare of the person in need. J Pers Soc Psychol. 2007;93(1):65-74. doi:10.1037/0022-3514.93.1.65
Advances in Medical Education and Practice

\section{Publish your work in this journal}

Advances in Medical Education and Practice is an international, peerreviewed, open access journal that aims to present and publish research on Medical Education covering medical, dental, nursing and allied health care professional education. The journal covers undergraduate education, postgraduate training and continuing medical education including emerging trends and innovative models linking education, research, and health care services. The manuscript management system is completely online and includes a very quick and fair peer-review system. Visit http://www.dovepress.com/testimonials.php to read real quotes from published authors. 